\title{
SCISOLA: REAL-TIME MOMENT TENSOR MONITORING FOR SEISCOMP3
}

\author{
Triantafyllis N. ${ }^{1}$, Sokos E. ${ }^{2}$ and Ilias A. ${ }^{1}$ \\ ${ }^{1}$ University of Patras, Department of Computer Engineering and Informatics, Rio 26504, Patras, \\ Greece,triantafyl@ceid.upatras.gr,aristeid@ceid.upatras.gr \\ ${ }^{2}$ University of Patras, Seismological Laboratory, Rio 26504, Patras, Greece, esokos@upatras.gr
}

\begin{abstract}
Automatic Moment Tensor (MT) calculation is exceptionally valuable in many realtime seismological applications, such as shake map generation or tsunami warning. Scisola, a new software for automatic MT retrieval, has been recently developed. This software binds the extensively used ISOLA MT inversion code with the widely known real-time seismological processing tool, SeisComP3. Automatic MT calculation is achieved by passing the event location information, the waveforms and the station meta-data produced by SeisComP3 to ISOLA. Scisola has been written in Python, many powerful libraries were used and significantly reduced the MT computation time by calculating the Green's functions and the centroid position/time grid search in parallel mode. This tool provides a graphical user interface for easy solution overview of the extended graphical output and a quick revision of the corresponding solution; a database for storing the results and an extensive configuration customized to the user's preferences. Apart from the real-time MT approach, scisola is capable of running in offline mode mostly for testing or playback purposes. Lately, a scisola plug-in was completed for real-time MT monitoring by automatically updating a Web page with the latest MT calculations. The code's performance was compared to manual MT solutions and proved to be satisfying.
\end{abstract}

Keywords: ISOLA, Python, automatic, inversion, focal mechanism.

\section{Пврі́ $\eta \psi \eta$}

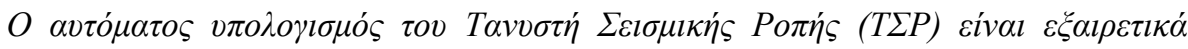

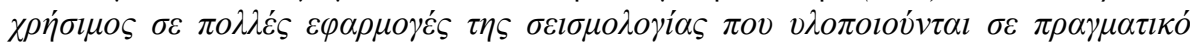

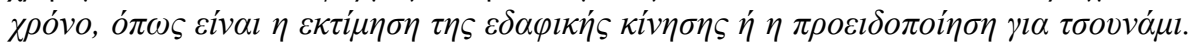

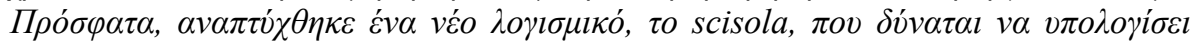

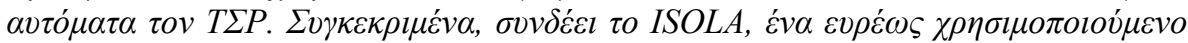

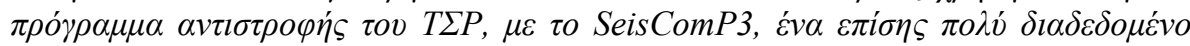

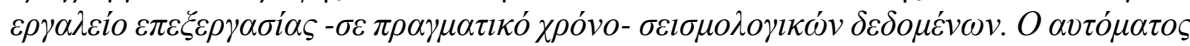

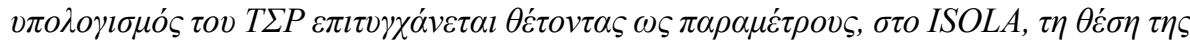

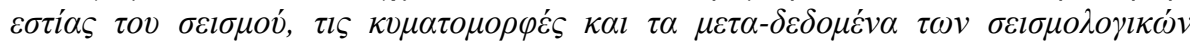

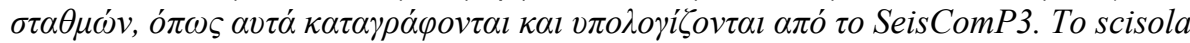

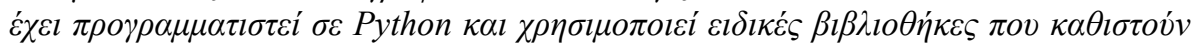

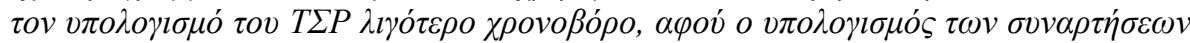

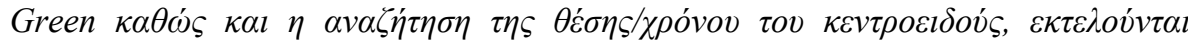

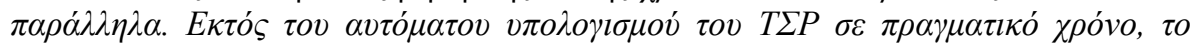

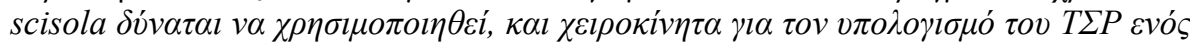




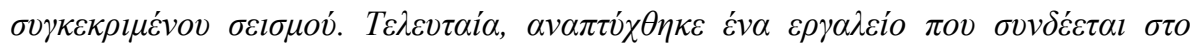

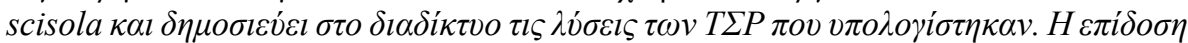

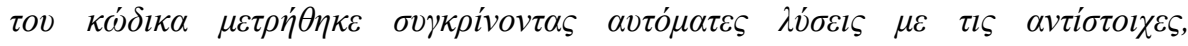

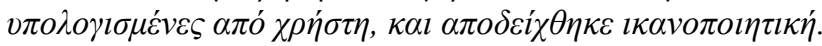

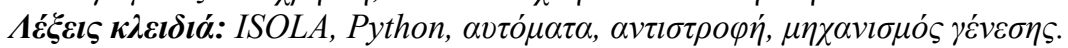

\section{Introduction}

Modern seismic networks with broadband sensors and real-time digital telemetry provide the opportunity for automating the Moment Tensor (MT) calculation. The MT inversion procedure can be categorized in calculations concerning global and regional networks. As regards the first case, Global CMT project (http://www.globalcmt.org) (Dziewonski et al., 1981; Ekström et al., 2012), the United States Geological Survey (http://earthquake.usgs.gov), the Earthquake Research Institute (ERI), Japan (Kawakatsu, 1995), the GeoForschungsZentrum (GFZ) German Research Centre for Geosciences (http://www.gfz-potsdam.de/en/home) (Saul et al., 2011) already support a global automatic MT calculation procedure. As for regional networks, the Berkeley Seismological Laboratory of the University of California developed the TDMT_INV software (Dreger, 2003) used for regional automatic MTs (http://seismo.berkeley.edu) related to earthquakes larger than 3.5 Moment Magnitude (Mw). This software was adjusted and also used by the Japan National Research Institute for Earth Science and Disaster Prevention (http://www.bosai.go.jp/e) and the Mediterranean Network (MedNet) of Italy (http://mednet.rm.ingv.it). Other institutes -worldwide- that contribute to regional automatic MT calculation procedures are the Swiss Seismological Service (http://www.seismo.ethz.ch/prod/tensors/index_EN) and the Earthquake and Volcano Information Centre of Japan (http://wwweic.eri.u-tokyo.ac.jp/index-e.html), while (Bernardi et al., 2004) presented the first automatic MT inversion procedure in the Europe-Mediterranean region. MT retrieval software packages for regional distances include FMNEAREG (Delouis et al., 2008) and (Maercklin et al., 2011), KIWI (Cesca et al., 2010; Yagi and Nishimura, 2011) and ISOLA (Sokos and Zahradník, 2008, 2013). The last one has been used for research applications, for example, (Agurto et al., 2012; Quintero et al., 2014) and as an MT inversion routine, since 2006, at the University of Patras, Seismological Laboratory, Greece (http://seismo.geology.upatras.gr), and since 2012, at the National Observatory of Athens (http://bbnet.gein.noa.gr), at the University of Tehran (http://irsc.ut.ac.ir/tensor.php) and at the Colombia Geological Service (http://seisan.sgc.gov.co/RSNC/index.php/tm). ISOLA's extension towards automatic operation (Triantafyllis et al., 2013) combined with the rapid evolution of the widely known seismological software, SeisComP3 (http://www.seiscomp3.org) (Weber et al., 2007), paved the way for the scisola (Triantafyllis et al., 2015) software implementation; a free and open-source code for automatic and real-time MT monitoring based on the ISOLA code and tightly connected to SeisComP3. The source code and the user manual of scisola can be found at GitHub hyperlink (https://github.com/nikosT/scisola).

\section{Overview}

The implementation of scisola was achieved by the utilization of various free software tools and libraries. Scisola uses the ISOLA Fortran software as its main core and -since it is written in Pythoncombines the use of powerful Python libraries such as, ObsPy (Beyreuther et al., 2010) which is used mostly for seismological calculations e.g. signal filtering and instrument response removal; matplotlib (Hunter, 2007) and NumPy (Van Der Walt et al., 2011) for plots generation and numerical computations respectively; PyQt4 for Graphical User Interface (GUI) construction; subprocess for wrapping the necessary modules of SeisComP3 and ISOLA; multiprocessing for parallelizing calculations e.g. the centroid position/time grid search; and finally MySQLdb (Dustman, 2010) and psycopg2 (Di Gregorio, 2010) for manipulating database e.g. storing results and handling stations meta-data. Figure 1, shows the scisola architecture schema, including the above mentioned tools and 
libraries. Recently, a new plug-in to scisola was developed -written in Bash and Web development languages- for real-time MT monitoring over the Internet.

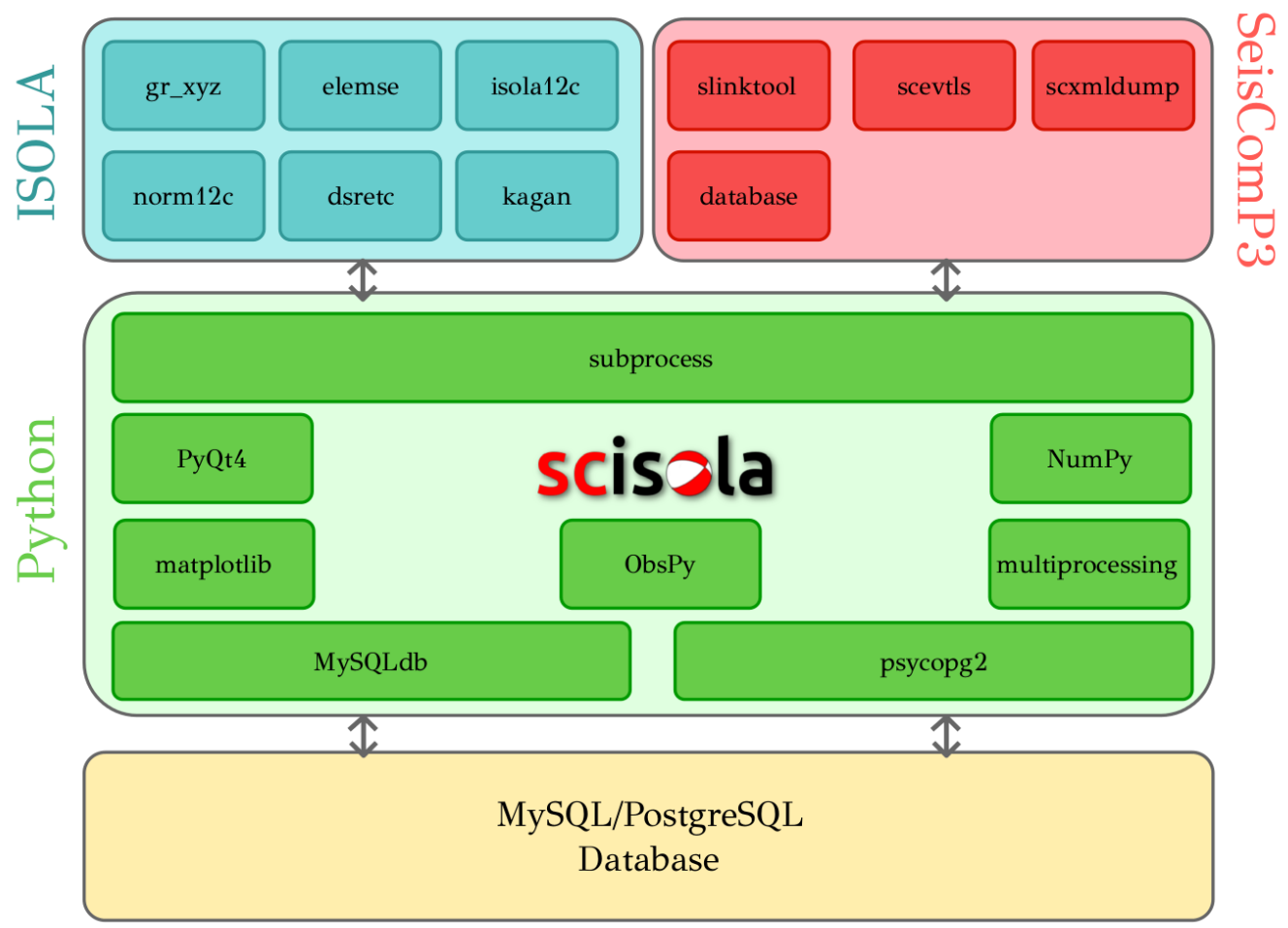

Figure 1 - Scisola architecture schema.

\subsection{ISOLA}

The ISOLA MT retrieval algorithm is based on the iterative deconvolution method (Kikuchi and Kanamori, 1991). Earthquake sources can be modelled as point or multiple point sources. Green's functions are calculated by the discrete wavenumber method (Bouchon, 1981) and (Coutant, 1989) for local or regional distances using one-dimensional velocity models. The MT is found by the leastsquares, time-domain minimization of the L2-norm misfit between the observed and synthetic waveforms, while the centroid position and time of subevents is optimized through grid search. The computational options allow for inversion using the full MT, the deviatoric MT or the double-couple (DC) constrained MT (Sokos and Zahradnik, 2008; Kř́žzová et al., 2013).

\section{Software description}

\subsection{Automatic Moment Tensor algorithm}

The automatic MT calculation procedure -accomplished in scisola- can be described in eight steps.

\subsubsection{Triggering the Moment Tensor procedure}

Triggering the MT calculation procedure can be performed in two ways; automatic and manual. In the first case, scisola is listening to SeisComP3 for new earthquakes and automatically triggers an MT procedure when it is being notified for a new event. This is implemented by using the watcher module of scisola code that combines the scevtls and scxmldump tools of SeisComP3. Additionally, scisola performs various checks at the incoming earthquake notification such as magnitude threshold 
and location constrains. Alternatively, in the manual mode, the MT calculation procedure is executed through Python scripting.

\subsubsection{Station selection by epicentral distance}

After the MT procedure triggering, scisola retrieves all station and stream meta-data from its database (which has been populated at the initial configuration). Afterwards, the algorithm removes streams that have unaccepted stream type or are blacklisted by the user. Thereafter, it calculates the distance and the azimuth of the stations based on the epicentre's location and selects those stations that fulfil a distance range rule, defined at the settings. Rules are based on the idea that more distant stations are used for larger magnitude events. In this way, it is more likely for clipped streams or stations, affected by the finite source dimension, to be avoided. The parameters could be roughly estimated from empirical relations, e.g. (Somerville et al., 1999). For example, for magnitude 6, 4, and 2 the characteristic fault length is $\sim 10,1$ and $0.1 \mathrm{~km}$, respectively.

\subsubsection{Data retrieval}

At the next phase, through seedlink module of scisola code, that uses the slinktool utility of SeisComP3, the software retrieves the available seismic waveforms in mini-seed format and removes those streams that have gaps or are clipped. The extraction time window is set according to the origin time and the time window length (tl) used in the inversion.

\subsubsection{Data correction and alignment}

At the next phase, scisola applies rotation to a geographic coordinate system (ZNE) and instrument correction based on stream meta-data (displacement waveforms are used in the inversion). If the orientation of a stream is not specified, it is removed from further processing. Additionally, waveforms are aligned according to the origin time and re-sampled to the same sampling frequency.

\subsubsection{Station selection by azimuthal distribution}

At this stage, eight azimuthal sectors of equal size are a priori defined while stations are distributed in these sectors according to their azimuth value, which was previously calculated based on the epicentre's location. The maximum number of stations per sector and the minimum number of sectors needed for MT calculation are set at configuration. If the minimum number of azimuth sectors is not reached, the inversion procedure terminates. In case the number of stations in a sector exceeds the maximum number, scisola will select those stations that have smaller epicentral distance and higher priority. Priority is set at configuration and it is based on user's knowledge about station performance.

\subsubsection{Green's functions computation}

During this step, Green's functions are computed through a Python wrapper to the ISOLA code, a 1D crustal velocity model is used and it is defined at configuration. Green's functions are later convolved with six elementary moment tensors to form elementary seismograms (Sokos and Zahradník, 2008; Kř́žová et al., 2013). The temporal variation of each elementary moment rate is a delta function. The centroid is grid searched beneath the epicentre. The depth distribution of the trial sources, including the grid step, are defined at the configuration. Scisola uses parallel processing and thus speeding up computation- by executing multiple threads, i.e. one thread for each trial depth Green's function calculation.

\subsubsection{Centroid Moment Tensor inversion}

After the Green's functions computation, the inversion procedure starts. Although the ISOLA code offers various options for source inversion, e.g. full MT, deviatoric, DC-constrained etc.; the deviatoric type is predefined, since it is adequate in most cases. The frequency band used in the inversion procedure is defined by the event's magnitude and is set up as a rule at the configuration. Rules are based on the idea that large events should be inverted using larger periods. The inversion 
frequency band is also affected by the crustal model; for example, full waveform modelling is commonly feasible up to epicentral distances of $\sim 10$ minimum shear wavelengths (Fojtikova and Zahradnik, 2014). Finally, a temporal range for the grid search of the centroid time is defined a few seconds before and after the origin time. The temporal grid search is additional to the spatial grid search, i.e. search of the centroid underneath the epicentre, thus a spatiotemporal grid search is finally performed.

\subsubsection{Results generation/plotting}

After successful computation of the inversion, scisola produces a number of output files, e.g. an ASCII file of the results suitable for distribution over the Internet, plots etc. Specifically, it generates a figure containing the beachball of the MT solution, a map containing the beachball of the DC part of the MT and the locations of stations contributing to the inversion, a plot of observed and synthetic waveforms, a simple plot demonstrating the best focal mechanism for each trial depth, a comprehensive plot of correlation contours with resulting focal mechanisms at each spatiotemporal grid point (the so-called correlation plot) and a plot of the contributing streams. Moreover, it creates a $\log$ file containing the process information throughout the entire computation. Finally, the results are stored in the scisola database $(M y S Q L)$. Figure 2, shows a review/revision window for a MT solution. The figure includes eight tabs concerning the results (e.g. detailed solution plot, map, correlation plot, text file, log file, etc.) and the revision panel -at the right part of the results tab-.

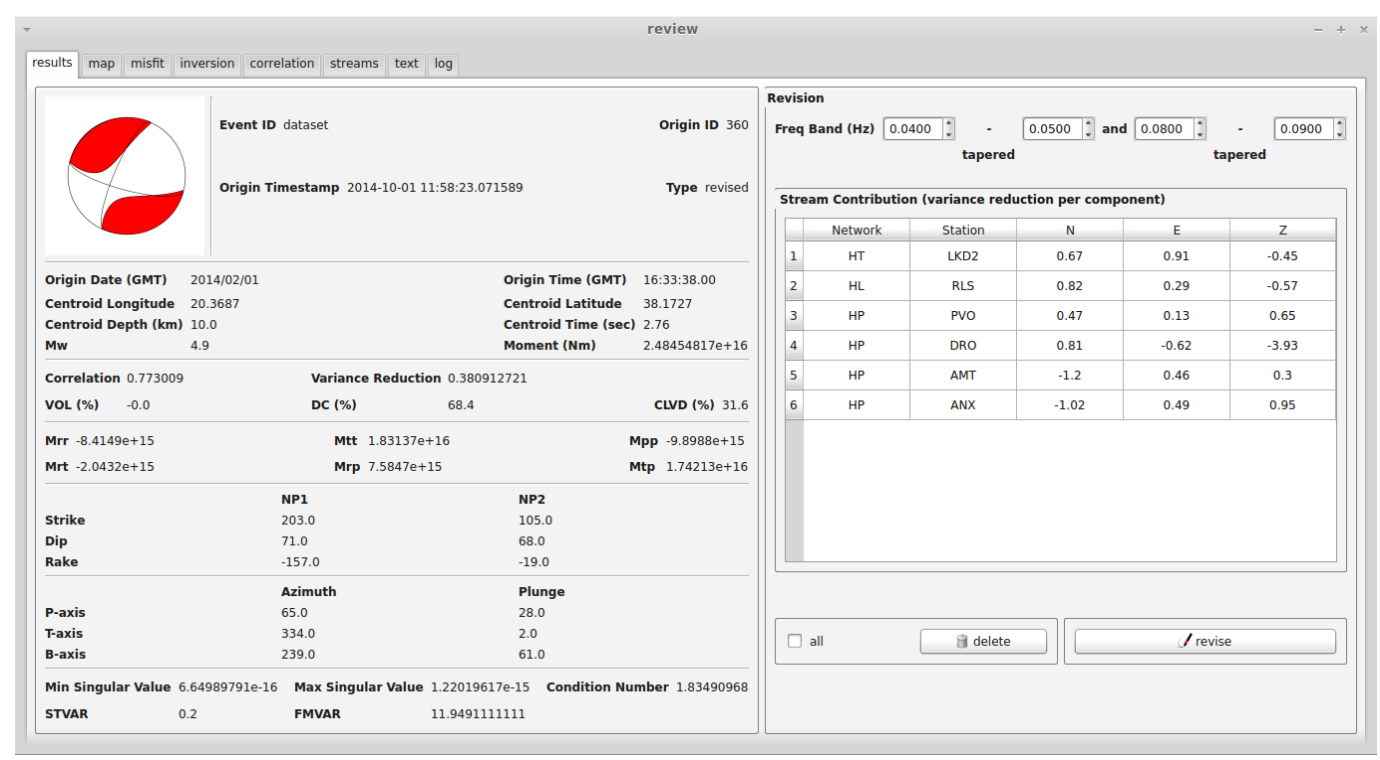

Figure 2 - Review/Revision window of scisola GUI for a moment tensor solution.

\subsection{Moment Tensor solution revision}

A quick revision of the MT solution can be performed by manual removal of individual, automatically selected streams and/or by changing the frequency range of the inversion. The variance reduction of each component after the inversion can assist the user to decide which components to remove, i.e., the ones with the worst fit. However, this is not always straightforward, see (Zahradnik and Plesinger, 2005, 2010).

\subsection{Moment Tensor solution's quality evaluation}

Scisola produces a few parameters that indicate the quality of a MT calculation. In detail, the Variance Reduction (VR) expresses the waveform fit ( $\mathrm{VR} \leq 1$, while $\mathrm{VR}<0$, implies no correlation). The Condition Number $(\mathrm{CN})$ characterizes the inversion stability; a ratio between the largest and smallest singular value $(\mathrm{CN}<3-5$, indicates well-posed inversion, while $\mathrm{CN}>10$, indicates ill-posed) 
(Kř́žová et al., 2013). The FMVAR and STVAR indexes, describe the focal mechanism variability and time space resolution of the centroid. FMVAR quantifies the focal mechanism variation within the high-correlation region and the STVAR quantifies the size of this region in the space-time grid search; large values of FMVAR and STVAR indicate instability of the solution (Sokos and Zahradnik, 2013). In addition, the scisola plug-in reports a quality factor (A-D) and (1-4) (A1 best quality, D4 worst). The alphabetical part is defined according to VR and the total number of stations contributing to the inversion. The numerical part is defined based on the percentage of the Compensated Linear Vector Dipole (CLVD) component in the solution (Scognamiglio et al., 2009). This quality factor determination scheme is followed by the GI-NOA for manual MT solutions. Illustration example of parameters' utilization is presented at Triantafyllis et al. (2015). We have to note that a robust scisola configuration set-up would significantly improve the automatic MT calculations. This includes careful determination of stations' priority, selection range, inversion frequency and more. Thus, a good user knowledge of networks' capabilities, telemetry malfunctions and the use of a training dataset are suggested in order to achieve a good performance of the software.

\subsection{Real-time Moment Tensor monitoring}

Lately, a plug-in to the scisola software was developed for real-time MT solutions monitoring over the Internet. This is obtained by automatically updating a Web page with the latest MT calculations. Specifically, the Web page offers a map hyperlink -as shown in Figure 3-, which is created using the Google Maps technology, next to a report list of the fifty most recent MT solutions. Every MT solution is depicted on the map based on its location and illustrated according to its focal mechanism representation. By clicking on the focal mechanism representation, a text balloon appears containing particular information such as centroid depth, centroid origin time, moment magnitude (Mw), solution's quality, a hyperlink to an HTML document with an extensive description of the MT solution and more. The MT solution hyperlink besides the comprehensive summary of the calculation, includes the generated series of the plots that were previously described. Additionally, the Web page offers a search area where the user can restrict the displayed MT solutions conforming to a specific Mw, centroid depth and/or location range. Furthermore, the Web page offers a list hyperlink that displays a line-up of the fifty most recent MT computations. Subsequently, the user, by clicking on the desired MT solution, will be redirected to the specific HTML document of the calculation -as described abovein order to review it. Moreover, the plug-in makes available the launching of a simple HTTP server that can quickly show the Web page for public view through the Internet. The plug-in installation can be easily performed by following the instructions of a set-up script.

\section{Comparison among automatic and manual Moment Tensor solutions}

A dataset of 46 earthquakes, occurred from 2014/01/02 to 2014/06/25 in Greece and analysed by scisola, was used for the evaluation of the MT's solution. The data were retrieved from the Hellenic Unified Seismic Network (HUSN), while the comparison to the automatic solutions has been achieved using the corresponding manual solutions provided by the Geodynamics Institute of the National Observatory of Athens (GI-NOA) (http://bbnet.gein.noa.gr). The comparison, however, is not completely straightforward. For instance, GI-NOA also used strong motion data and various crustal models according to the event's location, while we only used broadband data and a single crustal model (Novotný et al., 2001) for all events. Comparison has been accomplished using the so-called Kagan metric (Kagan, 1991). This angle expresses the minimum rotation between two double-couple focal mechanisms. An acceptable agreement between the manual and automatic solution is represented by Kagan angles up to a few tens of degrees, while a strong disagreement corresponds to angles larger than $50^{\circ}-60^{\circ}$ (Vannucci et al., 2004). 


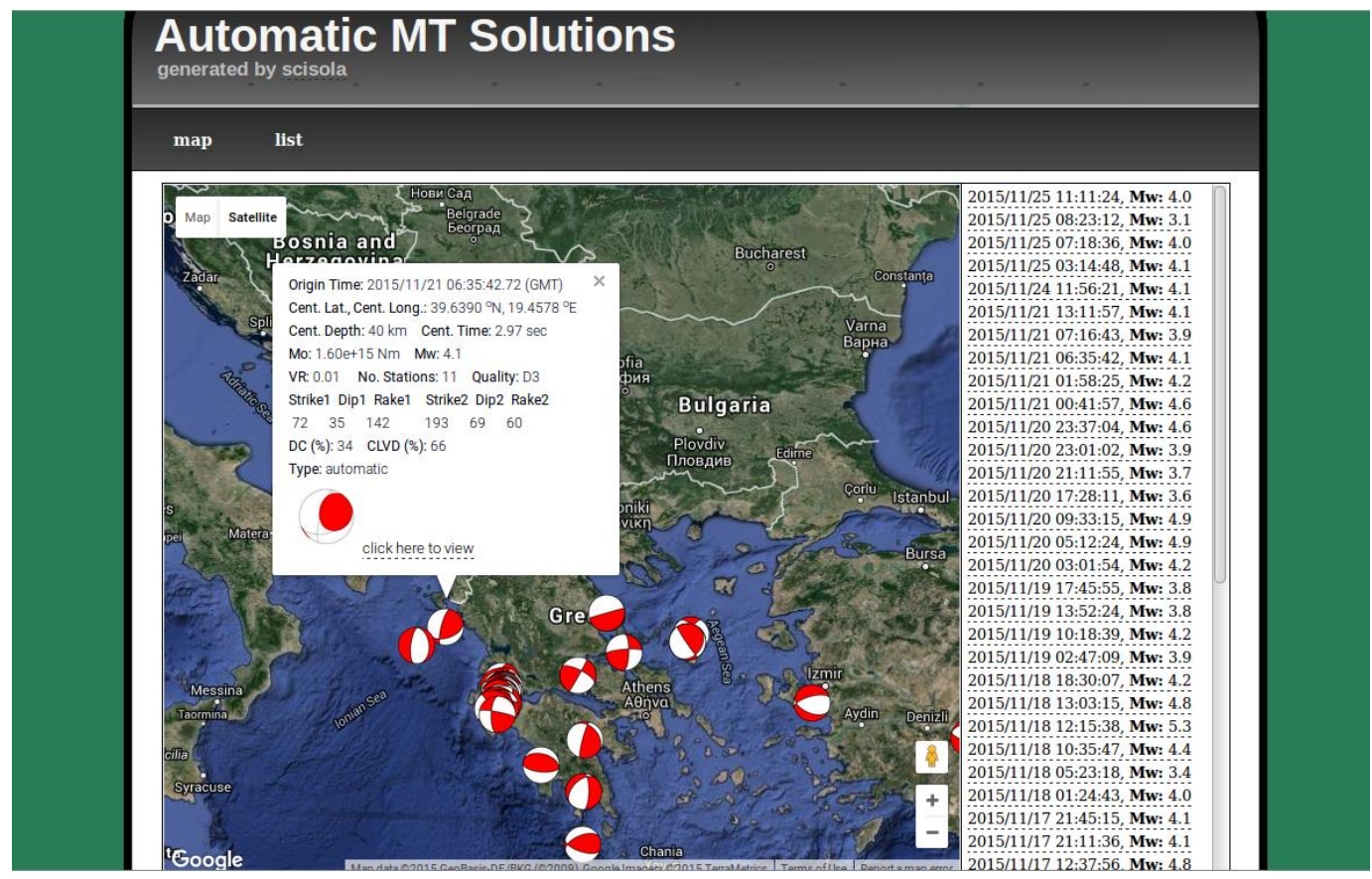

Figure 3 - Plug-in to scisola for real-time MT solutions monitoring over the Internet (map hyperlink).

We observe that 34 out of the 46 MT pairs have a difference of less than $30^{\circ}$. Apart from the focal mechanism estimation, two other parameters that are of great importance during the first minutes after an event's occurrence, are the moment magnitude (Mw) and the centroid depth. We note that 39 out of the 46 pairs under comparison provide almost the same size of the seismic source (i.e. Mw difference $\leq 0.1)$. Additionally, for the entire evaluation dataset, the maximum difference was not larger than 0.3. Figure 5 presents a histogram of the Mw and the Centroid Depth (CD) difference between the automatic and manual solutions. According to this plot, the focal mechanisms of 35 out of 46 earthquakes produce almost the same centroid depth of the seismic source (i.e. difference $\leq 4$ $\mathrm{km})$. Thus, scisola provides the size and the depth estimation of the seismic source with adequate accuracy a few minutes after the event occurrence. Extreme Kagan values are mainly related to large azimuthal gaps (i.e. events that occurred at the edges of the seismic network). The use of different sets of waveforms or crustal models, in some cases, produced larger deviations between the automatic and manual processing. Moreover, the presence of long-period disturbances in the seismic data (Zahradník and Plešinger, 2005, 2010) is another possible cause of low quality automatic MT calculation. We have to mention, as well, that there are some cases where the manual solution itself is not well constrained. For example, a poor depth resolution could cause large differences between automatic and manual solutions.

\section{Future improvements}

The results and the experience gained from the automatic MT application revealed possible extensions that would increase the reliability of scisola. Since, at present, only a single crustal model can be set, a next step towards MT computation improvement, is to implement multiple crustal models based on the events' location. In several cases, seismic data depict various problems such as data transmission problems, noise, disturbances (Zahradník and Plešinger, 2005) and more. Thus, advanced signal processing methods will significantly improve the procedure. Perhaps, these could detect erroneous waveforms (Vackár et al., 2014) and either remove them from the processing or even correct them prior to the inversion process. Additionally, pre-calculation of the Green's 
functions could speed-up the overall MT computation and thus allow a fully three-dimensional grid search of the centroid position.

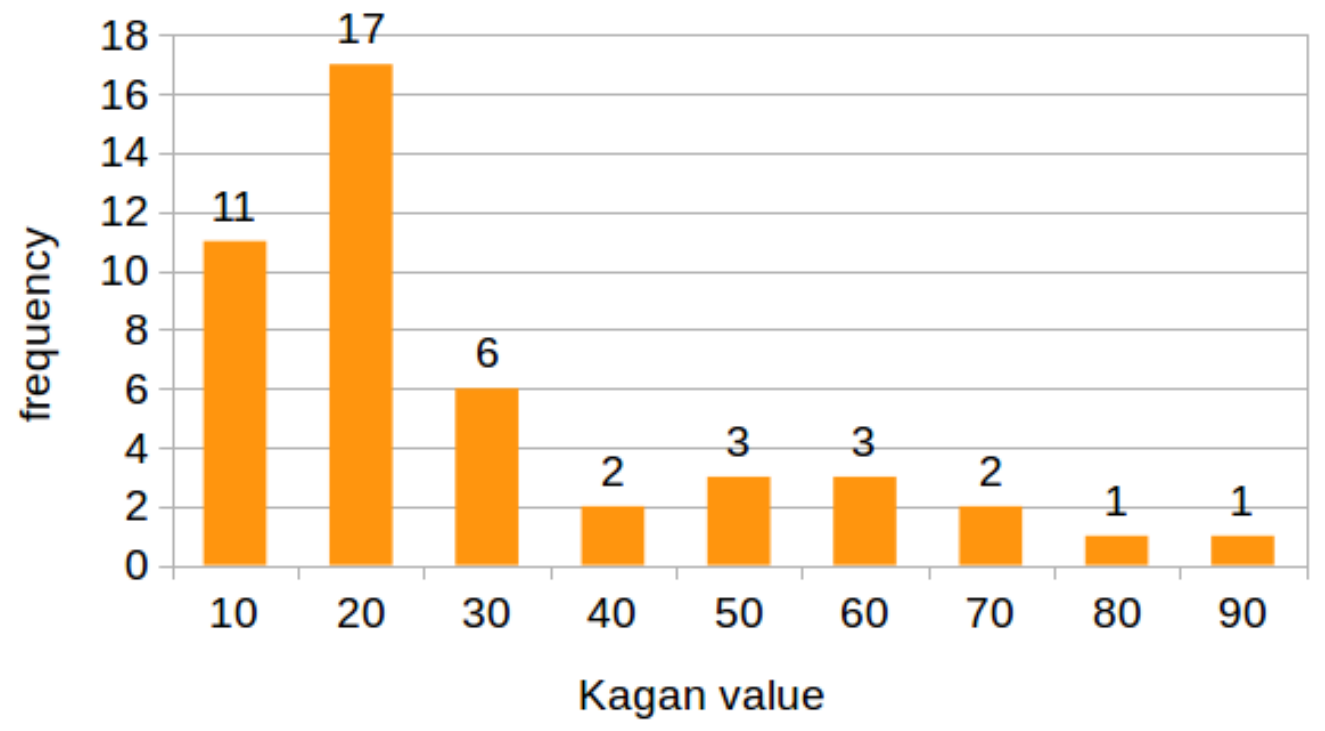

Figure 4- Kagan angle of miss-alignment $\left({ }^{\circ}\right)$.
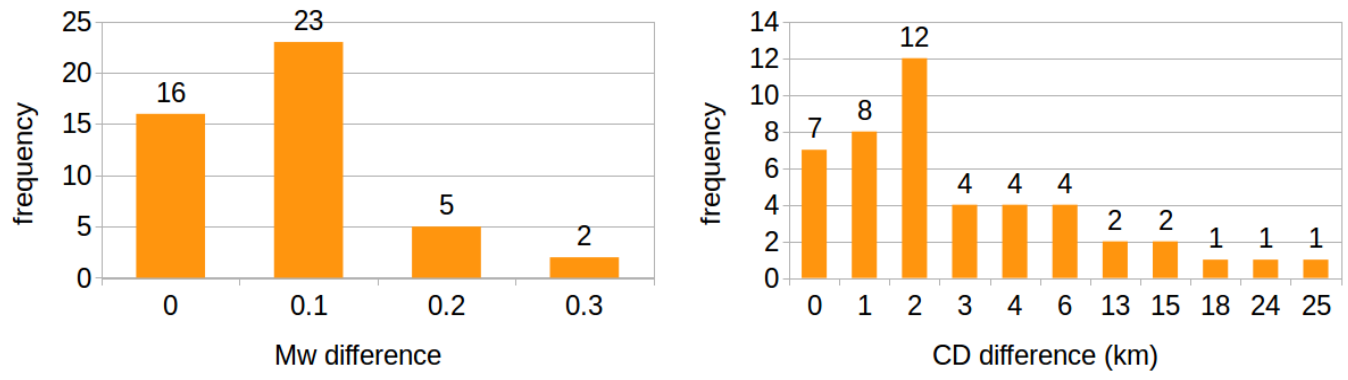

Figure 5 - Manual minus automatic Mw and Centroid Depth (CD).

\section{Acknowledgments}

The waveform data from the HUSN as well as the scisola's deployment support by the GI-NOA are gratefully acknowledged.

\section{References}

Agurto, H., Rietbrock, A., Ryder, I. and Miller, M., 2012. Seismic-afterslip characterization of the 2010 MW 8.8 Maule, Chile, earthquake based on moment tensor inversion, Geophys. Res. Lett., 39, L20303, doi: 10.1029/2012GL053434.

Bernardi, F., Braunmiller, J., Kradolfer, U. and Giardini, D., 2004. Automatic regional moment tensor inversion in the European-Mediterranean region, Geophys. J. Int., 157, 703-716.

Beyreuther, M., Barsch, R., Krischer, L., Megies, T., Behr, Y. and Wassermann, J., 2010. ObsPy: A Python toolbox for seismology, Seismological Research Letters, 81(3), 530-533.

Bouchon, M., 1981. A simple method to calculate Green's functions for elastic layered media, Bul. Seism. Soc. Am. 71, 959-971. 
Cesca, S., Heimann, S., Stammler, K. and Dahm, T., 2010. Automated procedure for point and kinematic source inversion at regional distances, Journal of Geophysical Research: Solid Earth, 115, B06304, doi: 10.1029/2009JB006450.

Coutant, O., 1989. Program of numerical simulation AXITRA, Tech. rep., LGIT, Grenoble, France (in French).

Delouis, B., Charlety, C. and Vallée, M., 2008. Fast determination of earthquake source parameters from strong motion records: $\mathrm{Mw}$, focal mechanism, and slip distribution, EGU General Assembly 2008, Vienna, Austria, 13 April - 18 April.

Di Gregorio, F., 2010. Psycopg: PostgreSQL database adapter for Python. http://initd.org/psycopg.

Dreger, D.S., 2003. TDMT_INV: Time Domain Seismic Moment Tensor INVersion, International Handbook of Earthquake and Engineering Seismology, 81B, 1627 pp.

Dustman, A., 2010. MySQLdb: a Python interface for MySQL. http://mysql-python.sourceforge.net.

Dziewonski, A.M., Chou, T.A. and Woodhouse, J.H., 1981. Determination of earthquake source parameters from waveform data for studies of global and regional seismicity, Journal of Geophysical Research: Solid Earth (1978-2012), 86(B4), 2825-2852.

Ekström, G., Nettles, M. and Dziewoński, A.M., 2012. The global CMT project 2004-2010: Centroid-moment tensors for 13,017 earthquakes, Phys. Earth planet. Inter., Volumes 200201, June 2012, Pages 1-9, ISSN 0031-9201, 10.1016/j.pepi.2012.04.002. Available online at: http://www.sciencedirect.com/science/article/pii/S0031920112000696.

Fojtíková, L. and Zahradník, J., 2014. A new strategy for weak events in sparse networks: the firstmotion polarity solutions constrained by single-station waveform inversion, Seism. Res. Letters, 85, 1265-1274.

Hunter, J.D., 2007. Matplotlib: A 2D graphics environment, Computing in Science and Engineering, 9(3), 0090-95.

Kagan, Y.Y., 1991. 3-D rotation of double-couple earthquake sources, Geophys. J. Int., 106, 709-716.

Kawakatsu, H., 1995. Automated near-realtime CMT inversion, Geophys. Res. Lett., 22, 2569-2572.

Kikuchi, M. and Kanamori, H., 1991. Inversion of complex body waves-III. Bul. Seism. Soc. Am., 81, 2335-2350.

Kř́žová, D., Zahradník, J. and Kiratzi, A., 2013. Resolvability of Isotropic Component in Regional Seismic Moment Tensor Inversion, Bull. Seismol. Soc. Am., 103, 2460-2473.

Maercklin, N., Zollo, A., Orefice, A., Festa, G., Emolo, A., De Matteis, R., Delouis, B. and Bobbio, A., 2011. The Effectiveness of a Distant Accelerometer Array to Compute Seismic Source Parameters: The April 2009 L'Aquila Earthquake Case History, Bull. Seismol. Soc. Am., 101, 354-365.

Novotný, O., Zahradník, J. and Tselentis, G.A., 2001. Northwestern Turkey earthquakes and the crustal structure inferred from surface waves observed in western Greece, Bul. Seism. Soc. Am., 91(4), 875-879.

Quintero, R., Zahradník, J. and Sokos, E., 2014. Near-regional CMT and multiple-point source solution of the September 5, 2012, Nicoya, Costa Rica Mw 7.6 (GCMT) earthquake, Journal of South American Earth Sciences, 55, 155-165.

Saul, J., Becker, J. and Hanka, W., 2011. Global moment tensor computation at GFZ Potsdam, AGU 2011 Fall Meeting (San Francisco 2011).

Scognamiglio, L., Tinti, E. and Michelini, A., 2009. Real-time determination of seismic moment tensor for the Italian region. Bulletin of the Seismological Society of America, 99(4), 2223-2242.

Sokos, E.N. and Zahradník, J., 2008. ISOLA a Fortran code and a Matlab GUI to perform multiplepoint source inversion of seismic data, Comp. Geosc., 34, 967-977.

Sokos, E. and Zahradník, J., 2013. Evaluating Centroid Moment Tensor Uncertainty in the New Version of ISOLA Software, Seismol. Res. Lett., 84, 656-665.

Somerville, P., Irikura, K., Graves, R., Sawada, S., Wald, D., Abrahamson, N., Iwasaki, Y., Kagawa, T., Smith, N. and Kowada, A., 1999. Characterizing crustal earthquake slip models for the prediction of strong ground motion, Seism. Res. Lett., 70, 59-80.

Triantafyllis, N., Sokos, E. and Ilias, A., 2013. Automatic moment tensor determination for the Hellenic Unified Seismic Network, 13th International Congress of the Geological Society of Greece, Chania, Greece, September 5-8. 
Triantafyllis, N., Sokos, E., Ilias, A. and Zahradník, J., 2015. SCISOLA: AUTOMATIC MOMENT TENSOR SOLUTION FOR SEISCOMP3, Seismological Research Letters, First published on December 2, 2015, doi: 10.1785/0220150065.

Vackáŕ, J., Burjánek, J. and Zahradník, J., 2014. Automated detection of disturbances in seismic records; MouseTrap code, Seismol. Res. Lett., 86, 442-450, doi: 10.1785/0220140168.

Van der Walt, S., Colbert, S.C. and Varoquaux, G., 2011. The NumPy Array: A Structure for Efficient Numerical Computation, Computing in Science \& Engineering, 13(2), 22-30.

Vannucci, G., Pondrelli, S., Argnani, A., Morelli, A., Gasperini, P. and Boschi, E., 2004. An atlas of Mediterranean seismicity, Editrice Compositori.

Weber, B., Becker, J., Hanka, W., Heinloo, A., Hoffmann, M., Kraft, T., Pahlke, D., Reinhardt, J. and Thoms, H., 2007. SeisComP3 - automatic and interactive real time data processing, EGU General Assembly 2007, Vienna, Austria. 27 April - 2 May.

Yagi, Y. and Nishimura, N., 2011. Moment tensor inversion of near source seismograms, Bulletin of IISEE, 45, 133-138.

Zahradník, J. and Plešinger, A., 2005. Long-Period Pulses in Broadband Records of Near Earthquakes, Bull. Seismol. Soc. Am., 95, 1928-1939.

Zahradník, J. and Plešinger, A., 2010. Toward Understanding Subtle Instrumentation Effects Associated with Weak Seismic Events in the Near Field, Bull. Seismol. Soc. Am., 100, 5973. 